\title{
A MULTI-SITE CASE STUDY OF HUMAN FACTOR CONSIDERATIONS AND MACHINERY UTILIZATION IN FOOD PRODUCING INDUSTRY
}

Adeyemi, Hezekiah Oluwole.; ${ }^{1}$ Akinyemi, Olasunkanmi Oriola.;'Lawal, Nurudeen Samuel.; ${ }^{3}$ Ade-Ikuesan, Olanike Olufisayo.; ${ }^{1}$ Makinde, Ajibola Abdullahi.; ${ }^{1}$ Adenuga Ayodeji.; ${ }^{1}$ Ojo Oluseye.

Department of Mechanical Engineering, Olabisi Onabanjo University, Agoiwoye, Nigeria.

Department of Agricultural Engineering, Olabisi Onabanjo University, Agoiwoye, Nigeria

Department of Electrical and Electronic Engineering, Olabisi Onabanjo University, Ago-iwoye, Nigeria

Corresponding Author's e-mail: adeyemi.hezekiah@oouagoiwoye.edu.ng

\section{ABSTRACT}

This study evaluated ergonomics consequences of maximizing industrial machinery usage on the operators. The main objective was to establish a relationship between human factor considerations and machinery utilization (MU). The MU, over a period of one year, was computed for 45 Bundling Food Packaging Machine (BFPM) in 6 sausage roll producing industries located in Southwest Nigeria. Machine hazard/safety checklists were used inform of questionnaire to carry out machinery inspections and the subjective perceptions of operators of the machinery with respect to work loads and exposures to machine related hazards. $82.2 \%$ of the BFPM had MU rated above $90 \% .92 .8 \%$ of the operators were affected by environmental load, $91.1 \%$ affected by physical load and $81.8 \%$ by ergonomics perception ratings (OEPR) $(r=0.025, \mathrm{p}=870)$. The independent sample t-test showed that MU had statistically significantly higher means of good percentage ratings $(92.9 \pm 4.8)$ compared to that of the OEPR $(39.187 \pm 17.07), t(88)=20.321, p=0.001$. The result showed that the groups calculated/response means were significantly different. The study concluded that the ergonomics factors maintained around the machinery were rated below the emphasis placed on its high production and quality

Keywords: ergonomics, machinery, operators, safety, production

Accepted Date: 29 May 2018

Introduction

Ergonomics is the scientific discipline concerned with the understanding of interactions among humans and other elements of a system. It applies theory, principles, data and methods to design in order to optimize human well-being and overall order to optimize human well-being and overal
system performance. Ergonomics is concerned system performance. Ergonomics is concerned
with the 'fit' between the user, equipment and their with the 'fit' between the user, equipment and their environments. In machine designs, ergonomics aspects considerations include among others, handling of loads, postures, design of machine parts, graphical user interface, actuators and displays (Jan et al, 2012; Ashrafi and Khan, 2005; Mason, 1984). Design Ashafl and Khan, adapts machine to the user.
Ashraf et al., (2003) stated that some machinery in the industries is never assessed in terms of ergonomics, whereas one of the main causes of most industial accidents is inatequate use machine interaction and that unless the ergonomics lessons relating to machine usage are fully learned disaster could still continue to occur. If human factors considerations important in machine usage are not adequately provided, it will cause physica and emotional stress. This will also affects machine operator performance that will result into low productivity and poor quality of work. Ergonomic improvements in machinery handling will enhance operators' productivity while ergonomically designed designed equipment and proper safety training can significantly reduce high level of industrial accidents most especially among machinery handlers (Munipov, 1992; Brian et al. 2015; Arun etal. 2013).

Machinery is considered central to production process among the consumer goods industry. Therefore most industrialists strive to optimize assets and measure their ability to help meet overall goals. Fast-moving trends in production are adopted to reduce the time interval between the design of a product and delivery to the point of sale. Hence high-speed machining has been touted as a solution for maximizing machine efficiency in this direction (Alesa, 2009). The benefits to achieve are rist product quality and helps the line operate at peak performance among others. According to Melis (1989), in other to achieve an optimal balance between performance, quality and cost, machinery optimization is a main concern of food producing industry.

Subramaniam et al. (2009) mentioned that humans play a major role on the industrial shopfloor. $\mathrm{He}$ is typically actively involved in the decision-making process, operates semi-automatic machines help preatly to meting prearly to meeting mangents personnel directly working with machines involve in one manual handling or the other. Meanwhile biomechanics has obvious direct relevance to manual handling work on machine. Muscles must move to carry out tasks and how much physical work a worker can do depends on the biomechanical criterion (how much can be handled without damage to the body), physiological criterion (how much can be handled without over criter criterion (It is however very difficult to set definitive criteria for repetitive work, because even very light levels of work may cause increase in intramuscular pressure, which may sometimes lead to swelling of muscle fibres, pain and reduction in muscle strength (Stellman, 1998). Postures at work can also be influenced by individual differences, age and sex. It was mentioned by Wolfgang and Joachim (1998) that a "best" posture in manual handling is largely fiction. Hence the are a nuber of altergely "bes" postures from the sandpoin of differe "best" postures from the standpoint of different criteria.

Therefore improving occupational health and safety (OHS) and workers' productivity are the major challenge of many industries, especially in the developing countries like Nigeria. Some of the industries not adequately designed as a proper indus berce between worker abifies and job demands, poor human-machine system design and inappropriate management programs. These lead to workplace hazards, poor workers health, mechanical injuries, disabilities, and all these in turn reduces worker productivity, product/work quality and increases cost(Ashraf et al., 2003). Because of the diversity in machinery usage in industries, there must be proper assessment of the risk involved to the personnel working with the machines. Workers Workers pre aware of the risks and follow safe work practices that is attached to working with machines(Willy and Robert, 2006; Subramaniam, 2009; Mary, 2014).

This study investigated the ergonomics effect of maximizing industrial machinery on machine operators using some food producing (sausage roll) machinery (Bundling Food Packaging Machine-BFPM) in some parts of southwes Nigeria. The objectives were to evaluate the machinery usage, effects on workers, management decision as it affects the machine handlers and establish a relationship between human factor consideration and machinery utilization (MU)

Significance of the study

The study measured the importance placed on industrial machinery operators in comparison with the attention given to utilizing the machinery helped the management identify the subjective perceptions of a group of their work force and the gap to bridge regarding ergonomics program(s) put in place and the efforts at promoting safe working environment.

\section{Material and Methods}

Subject selection

Bundling Food Packaging Machine (BFPM) common among the selected food processing industries was selected for the study. BFPM is widely used by many food industries. It can store huge quantity of foods before they wrapped as a single bundle. All personnel (operators) working directly with the machines who were adequately experienced on the job and have spent at least 365 
days continuously on the machine were selected for the study. At least 2 operators (one on each shift) on each machine were assessed. In total 150 operators were involved. All potential volunteers agreed, and consents were obtained in written form to have the interview conducted after they were informed that their participation in the study was voluntary. The purpose of the study was stated and the confidentiality of the information provided were assured.

\section{Study areas and the research tools}

Six sausage roll producing industries located within Lagos, Oyo and Ogun states, the Southwest Nigeria, were included in the study. Structured questionnaire, modified from machine checklists (Industrial Accident Prevention Association, 2008; Gorge Manson University, 2011) and other authors as guided by Gunnar (1990), Hollmann et al (1999) and Workplace Safety \& Prevention Services

(2013) were used and supplemented with face-toface interviews. These were the research tools use for collection of information on the attitudes, needs and expectations of the machine handlers. The questionnaire construction addressed the subject areas as personal background, work background, typical workday/shift plan, current work, work organization, technical ergonomics an psychosocial factors. It measured the operators' physical load (such as body posture, repetitiveness), mental load (job stress) and environmental loads (machine speed, noise, vibration). The subjects were asked to assign numbers to stimuli of different intensities in such way that the numbers given match their ergonomics perceptions and vary directly in proportion to them. gory ratio $(\mathrm{CR})$ scale from 0 to 10 were used as shown in Table 1. Ten (10) is defined as the strongest effort and exertion a person experienced on the job.

Table 1: Category ratio scale and interpretations

\begin{tabular}{cc}
\hline Category ratio Scale & Interpretation \\
\hline 0 & Nothing at all \\
0.5 & Extremely weak \\
1 & Very weak \\
2 & Weak \\
3 & Moderate \\
5 & Strong \\
7 & Very strong \\
10 & Extremely strong \\
\hline
\end{tabular}

\section{Measurement of Machinery Utilization}

Use of BFPM was common among the industries accessed. Hence machinery utilizations were calculated, for 45 BFPM, using the ratio of actual output to the output that could be achieved if a plant ran at its maximum capacity for 365 days per year while producing $100 \%$ quality product. The actual outputs of the machines over a period of one year were obtained from the mer a per of we maximum capacity were derived from the manufacturers manual. Hence the MU was computed using (1) (Ellis, 1998)
Asset Utilization $=\frac{(\text { Average Production })}{/ \text { (Production Capacity })} \times 100$ Data Analysis and Statistical tests

Statistical Package for the Social Sciences (SPSS) results (in percentage) were compared with the percent (OEPR) (in rho was used for significance tests of correlatio coefficients at a p-value of 0.05 . According to Gerstman (2006), correlation quantifies the extent was used to analyse the collected data. The $45 \mathrm{MU}$ operators' perception self-ratings (OEPR) ( percentage) for corelation strength. Spearman's to which two quantitative variables go together. Correlation strengths can be classified as weak, $0<|\mathrm{r}|<0.3$; moderate, $0.3<|\mathrm{r}|<0.7$; and strong, $|\mathrm{r}|>0.7$. The independent sample $t$-test was used to analyse the means of the unrelated groups at $<0.05$. According to Pagano (2004), the independent samples t-test evaluates the difference between the means of two independent groups. It appraises whether the means for two independent groups are significantly different from each other. The independent sample $\mathrm{t}$-test is probably the

Table 2: The statistic information about the workers studied in six food producing industries.

\begin{tabular}{lccc}
\hline Description & $\begin{array}{c}\text { Job } \\
\text { Experience } \\
\text { (years) }\end{array}$ & Age & $\begin{array}{c}\text { Operating time } \\
\text { (hours) }\end{array}$ \\
\hline Mean & 3.6 & 27 & 9.4 \\
Mode & 3 & 25 & 8 \\
Standard Deviation & 3.5 & 3.1 & 2.0 \\
\hline
\end{tabular}

\section{Reported effect(s) of machinery on workers}

From Figure 1, more than $90 \%$ of the group of workers reported that the machines they operated were properly guarded $(94.4 \%)$ and that oil spillages were cleaned up almost immediately 96.8\%) About $90 \%$ also highlighted that machine ( (9.8\% of the operator ieported that the s the machine was high for them and would have

preferred working at a slower pace, while $68.8 \%$ of them complained of excessive machine noise. As $68.2 \%$ and $58.7 \%$ mentioned that emergency stop and warning labels respectively were put in place, $65 \%$ complained that the orientations of the machines did not permit keeping a natural posture during operations and that the arrangement of machinery limit their free movement. 
Operators' reported management measuresat improving occupational safety

As shown in Figure 2, $72.5 \%$ of the workers As shown in adequate free medical care. $64.2 \%$ believed they were given enough instruction on the machine they

worked with but only $48 \%$ stated that they enjoyed regular direct trainings on safety related. $52.6 \%$ saidthey were provided with usage was enforced. However 75.2\% c0mpand $71.2 \%$ desired for more recovery time.

\section{No available free medical services}

No provision of, and enforced, PPE usage

No regular trainings on safety measures

No adequate instruction on my machine

Shift-work disturbs my normal rest

Need more recovery time

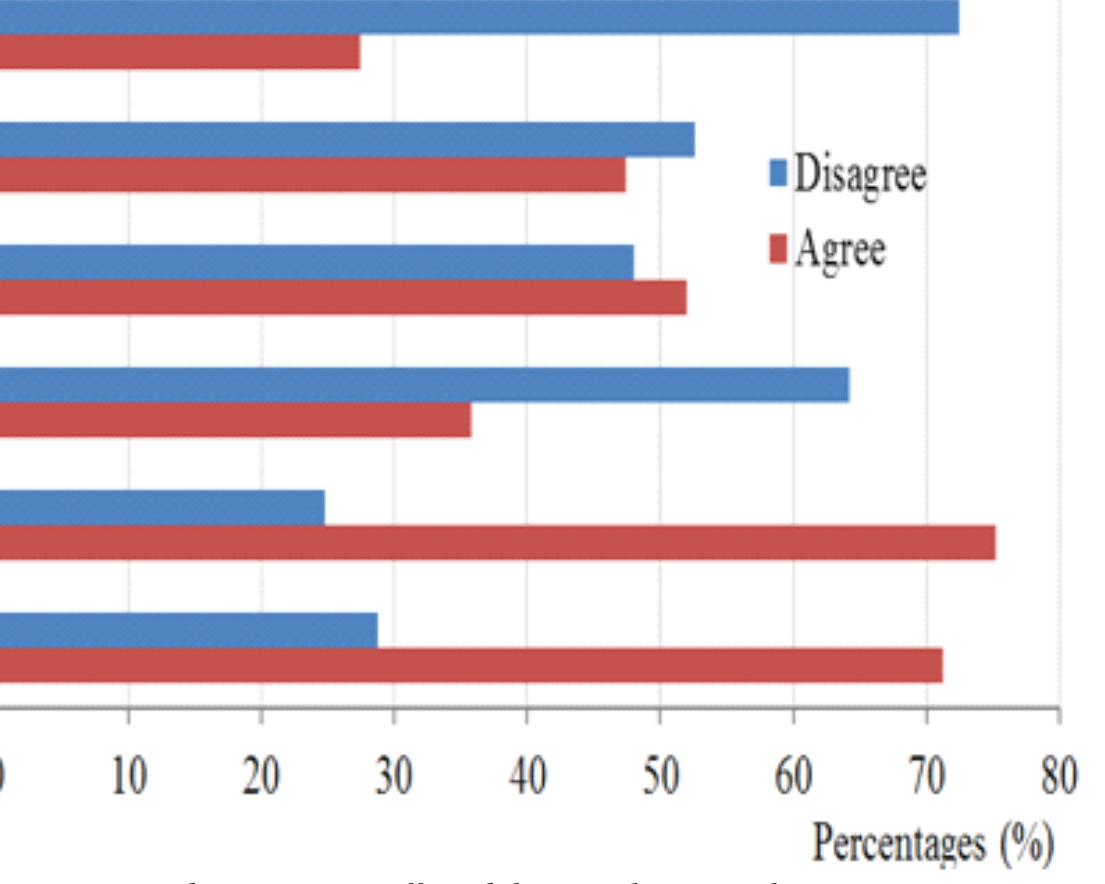

Fig. 2:Operators' reported management decisions as it affected their works on machine

Subjective perceptions of operators regarding workload elements

Figure 3 showed the measure of some selected workload elements affected by th workers and the rating' interpretaton of workers and the ratings' interpretation as aforementioned (Table 1). A total of $92.8 \%$ of all

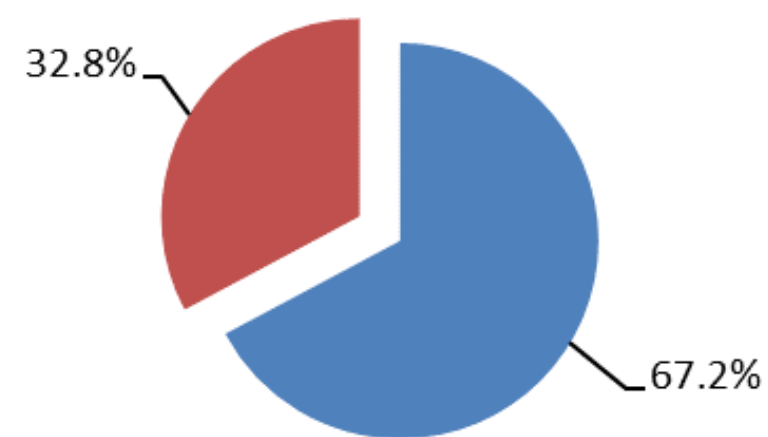

$\square$ Disagree $\quad$ Agree

Fig. 3: Operators' perceptions and responses to workload element

scale of $8.8(88 \%)$ was allotted to work pace, 7.5 $(75 \%)$ for job demand, $6.8(68 \%)$ for noise $67.2 \%$

About ninety two percent $(91.9 \%)$ of the subjects complained of physical load influence. In this category, an average rating of $5.75(57.5 \%)$ was cassigned to manul lifting on assigned to mer

Almost $83 \%$ of the operators were afflicted by

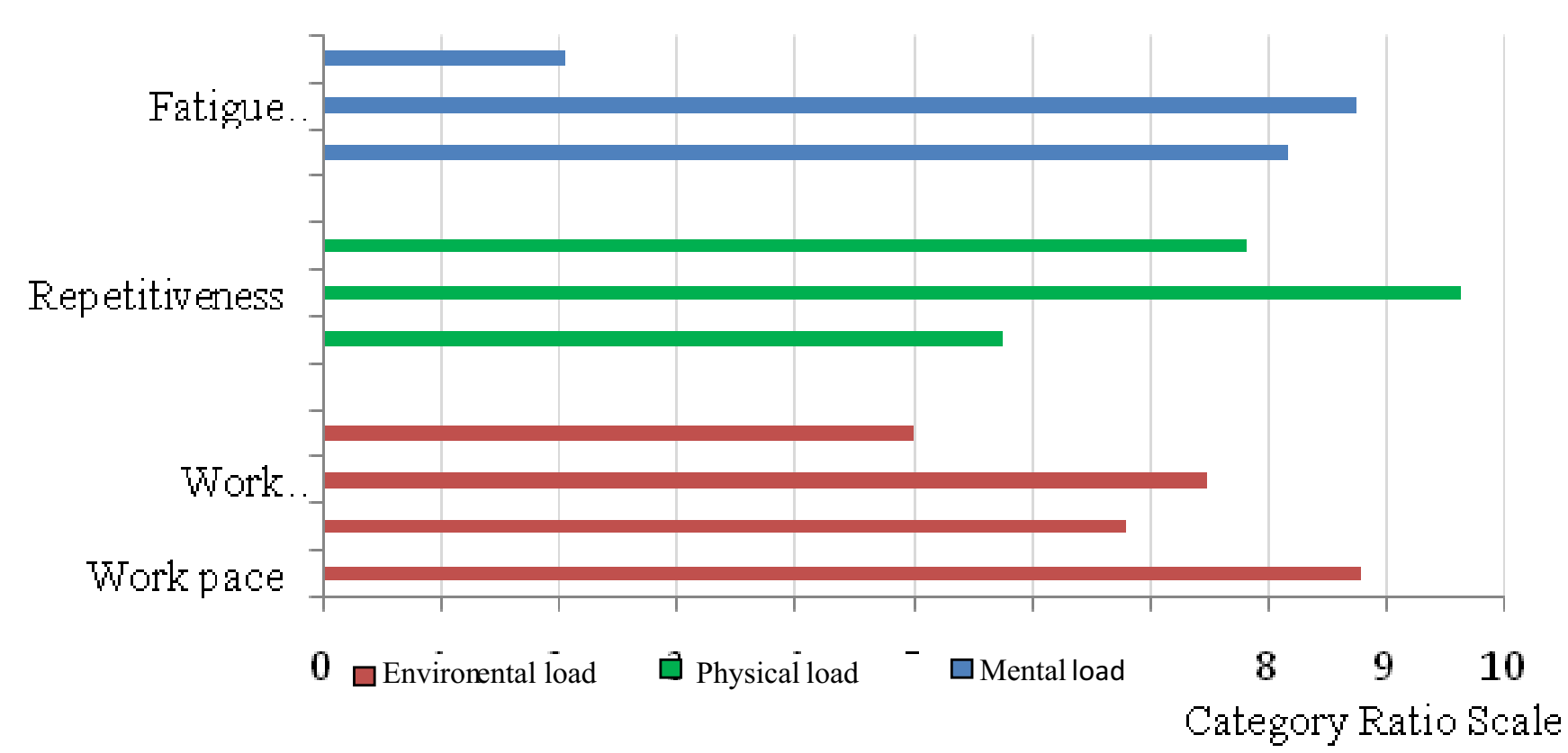

Fig. 4:Workers'perceptions on management position on production and/or quality and the human factor consideration

Average total reported on the job ergonomics criteria enjoyed by the operators

About $32 . \%$ of ap the BepM operars opined and erators opined and reported that their safety and health were the priority of the management as against $67.2 \%$ of their equals in the task who perceived that their managers placed greater emphasis on high production and quality more than meeting their ergonomics related demands.

\section{Machinery Utilization}

Using the formular as presented in equation (1) earlier, the $45 \mathrm{MU}$ were calculated and some parts of Figure $5 \mathrm{a}$ and Figure $5 \mathrm{~b}$ showed the outcomes. Nineteen (19) out of 23 representing $90.5 \%$ in Fig 5 a had MU, over a period of one year, above $90 \%$ mental load. Of this percentage, an average scale of $8.75(87.5 \%)$ was allocated by the workers for fatigue after daily work, $8.18(81.8 \%)$ allocated to job stress while 2.05 (20.5\%) was for job satisfaction. while 18 out of 21 representing $85.7 \%$ in Figure $5 b$ had its AU above $90 \%$. In general 37 out of 45 , representing $82.2 \%$, were above $90 \%$ and the production were rated good.

Ergonomics considerations versus machinery utilization

Comparing operators' ergonomics perception elf-ratings (OEPR) with machine MU

Figure 5 also compared the MU which were rated good and the operators on the job comfort selfratings. About $32.8 \%$ of all the operators were well satisfied with the ergonomics measures put in place and enjoyed on the job, while $82.2 \%$ of the machines they operated were rated high in terms of 


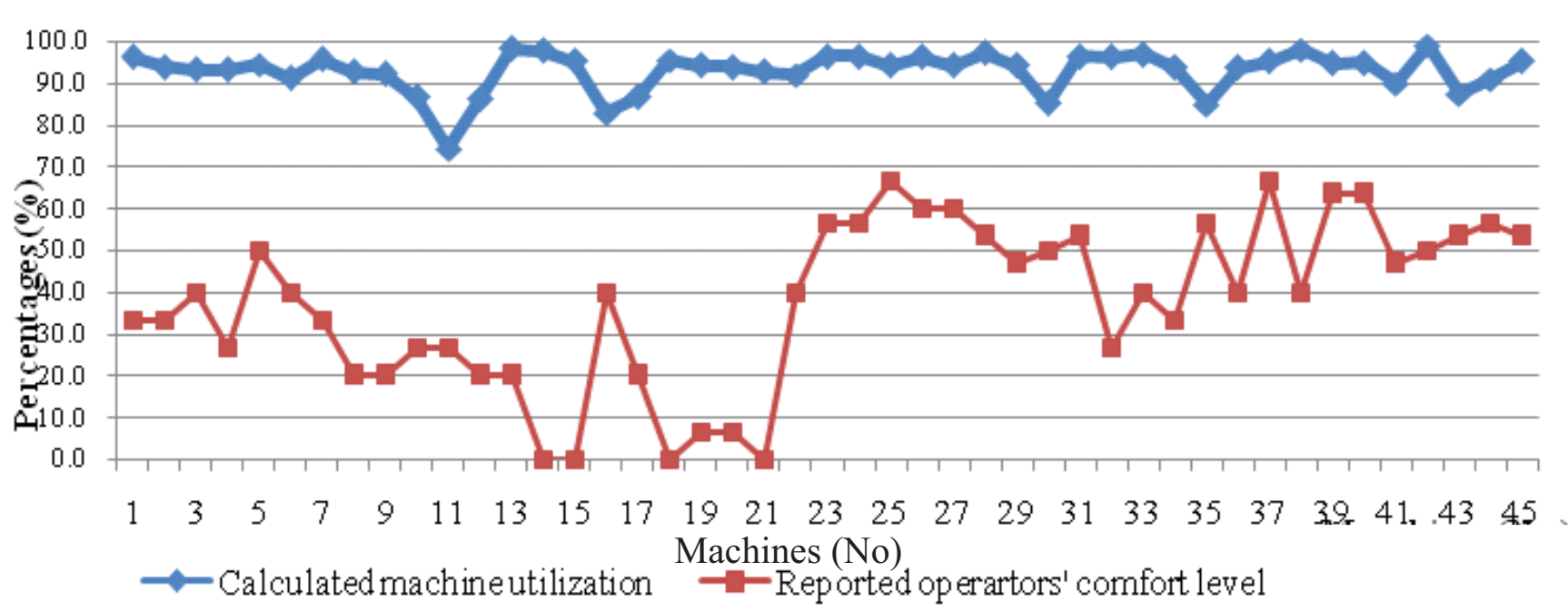

Fig. 5:Machinery utilization level for the studied BFPM and the reported operators' on the job comfort self ratings

\section{Spearman's Rank Correlation coefficient}

Cort

After comparing the result of MU with that of OSPR for correlation strength using Spearman's rho, $\mathrm{r}=0.025$ and $\mathrm{p}=.870$, hence the correlation is not significant. The coefficient of determination of 0.025 suggests $97.5 \%$ variability.

\section{Independent samples t-test between $M U$ and}

\section{OEP}

The t-test to determine the mean difference between MU and OEPR found that MU showed a statistically significantly higher means value (92.9 $\pm 4.8)$ compared to OEPR $(39.187 \pm 17.07), t(88)=$ $20.321, p=.000$. However, the groups' means were significantly different because the value of "Sig. (2tailed)" was lower than 0.05 .

\section{Discussions}

More than $80 \%$ of the total group of workers (operators) involved in the study complained of one level of discomforts or another from environmental, physical and mental load. Repetitiveness, too fast work-pace,fatigue after work and job stress were leading among all other complaints. Other significant discomfort rated between 'strong' and 'extremely strong' by the subjects included job demand, noise disturbance, lifting, inability to maintain natural postures at work among others. On the response to management's efforts at improving their on-the-job comfot and/or safety and heath level, less tob $50 \%$ mentioned to have regularly enjoyed direct

on-the-job trainings on safety. Whereas more than $70 \%$ complained that the shift-work characterized by their job disturbed their normal rest and craved for more recovery time. In their opinions, majority of the group of workers (about $70 \%$ ) opined that their enhanced comfort demands did not make the priority list of their managements but rathe believed that greater emphasis was placed on meeting daily production targets and qualities than they were concerned about their desired enhanced com the view earlier reported by Ashraf et al. (2003) that most industrial machinery do not meet ergonomic criteria of their handlers.

Machinery utilization (MU) as used in this stud was a metric that focused on how the efforts of managements translated to high production targets. More than $80 \%$ of all the BFPM evaluated had their utilization ratio above $90 \%$ and the assets were rated properly functioning. The result showed closed gap between what the machines were capable of producing and what they actully capable of producing and wh produced. However when the MU results we compared with the operators' ergonomic perceptio ratings (OEPR), the correlation is not significan and the groups' calculated/response means were significantly different. Hence the efforts in place at making the BFPM yield high level of production were not the same as the one in place to enhance the machine operators' on the job comfort level.

Both manpower utilization and machine efficiency are said to be the leading major factors contributing to production line efficiency (Subramaniam, 2009).
As observed from this study, the industries, at least for a period of one year, were able to properly utilize their production assets but the manpower directly involved seemed not satisfied ergonomically, going by the concerned workers' opinions. However, it is to be emphasized that in meeting targets, human play a vital role in the production floor and machine operators are valuable help in achieving management targets. However man is prone to environmental changes. When the performance of a machine handlers is reduced as a result of either a mechanical or other form of injur the productionquantity and/orquality also drops. From the group of workers responses, it can be deduced that the operators were aware of the importance of ergonomics factors to their health and safety and expected the ergonomics criteria to be highly captured in their work space and/or efforts at meeting the set target. It seemed that the operators were not satisfied with the second hand information/trainings received from their supervisors. They wanted a direct training program suprvisoritied Heath and Safety professiom from qualified Healh and Safety professionals. Therefore effors at enhancing the conforts level and/or health and safety of workers attached to production machinery is worth investing on. The feedback will be high standards of production and enhanced profits. This will reduce complaints of not been able to cope with the rate at which the work is expected to be performed. When emphasising efficiency, two goals should be paramount-the quality use of manpower and the engagement of appropriate MU

There is therefore the need for a better mechanism that will take into account the state of the operators while optimizing the MU. The mechanism should be equipped to suggest how the operation of the machines should be optimally adjusted, relevant trainings to be administered on the operators, optimal review of allocation of job to individual and stress relief package for workers.

One of the limitations of the present study is the One of the limitions the effects may under estimate the real-world opinions of the entire group of workers. Future efforts may however consider a wider coverage and other industries different from food producing. Lack of baseline information gathering is also an issue.

\section{Conclusion}

The study investigated the ergonomics effect of maximizing machinery usage on operators using some sausage roll producing industries in some parts of Southwest Nigeria. From the study, more than $80 \%$ of all the bundling food packaging machine evaluated had their utilization ratio above $90 \%$ and the performance of the assets were rated good. However, repetitiveness, too fast work-pace, fatigue after work and job stress were leading mong all other complaint by more than $80 \%$ of che

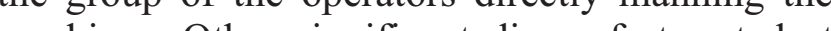
least 'strong' included job demand, noise disturbance, frequent manual lifting, inability to maintain natural postures at work. While more than $50 \%$ of them craved for direct relevant trainings, $70 \%$ complained that the shift-work disturbed their normal rest and craved for more recovery time. In their opinion, about $70 \%$ opined that their desired ent comfort level on the job was not part of the priority list of their managements as greater emphasis were placed on meeting daily production targets and quality. Machinery utilization (MU) results compared with the operators' ergonomics perception self-ratings showed that the correlation is not significant and the groups calculated/response means were significantly different. The study suggested development of a better mechanism that will take into account the state of the operators while optimizing the MU. This will help to sustain and/or enhanced the level of occupational safety and health advocated by International Labour Organization standards among the groups of workers.

\section{REFERENCES}

Alesa, L. (2009). Maximizing Machine Efficiencies, Available from https://www.gibbscam.com. Accessed July 3,2016.10.

Arun N. Cijo, M., Vinod, Y. (2013). Improvement of Ergonomic Factors That Affects Employees in a Textile Industry International Journal of Engineering Science and Innovative Technology 


\section{(IJESIT) (1), 276-283}

Ashraf, A. Shikdar, Naseem, M. S. (2003). Worker productivity, and occupational health and safety issues in selected industries Computers \& Industrial Engineering 5: 563-572

Ashrafi, K. A and Khan, I. A. (2005) Effect of noise pollution on hearing. Pak J Otolaryngol. 21(2):33-34

Brian M. K.,Lawrence, J. H., David, M. D.,YuangHsiang, H., and Peter E.D. L. (2015). Sociotechnical attributes of safe and unsafe work systems. Ergonomics. 58(4): 635-649.

Ellis R. (1998)Asset Utilization: A Metric for Focusing Reliability Efforts. Seventh International Conference on Process Plant Reliability, October 25-30, Marriott Houston Westside Houston, Texas Available from www.plant-maintenanceresource-center.com/articles/assetutilization.Accessed August 13, 2016

Gerstman, B.B. (2006). Correlation. Available online at: www.sjsu.edu/, Accessed 17 May 2015

Gorge Manson University (GMU). (2011). Machine and machine shop safety guide. Available from www.ehs.gmu.edu. Accessed November 18, 2014,

Gunnar, B. (1990). Psychophysical scaling with applications in physical work and the perception of exertion. Sc and J Work Environ Health, 16(1): 55 - 8

Hollmann S, Klimmer F, Schmidt K-H, Kylian H (1999) Validation of a questionnaire for assessing physical work load. Scand J Work Environ Health ; 25(2):105-114

Industrial Accident Prevention Association (IAPA). (2008). Machine safety. Available from www.iapa.ca Accessed April 15, 2015,

Jan D. Ralph, B., Peter, B., Pascale, C., Pierre, F. William, S. M., John, R. W. Bas, D. (2012). A strategy for human factors/ergonomics: developing the discipline and profession, http://dx.doi.org/10.1080/00140139.2012. 661087, Taylor \& Francis 1-27

Mary, C. (2014). Man versus Machine or Man + Machine? Published by the IEEE Computer
Society. Available from http://hal.pratt.duke.edu/sites/hal.pratt.duk e.edu. Accessed April 2, 2016

Mason, R. M. (1984). Ergonomics: The Human and the Machine. Library Journal, 109(3):33132.

Matthew, R. (2004). Advanced Research Methods in Psychology. Available online at www.psychologyaustralia.homestead.com, Accessed on 12 September 2013

Melis, T. (1989) Packaging Manager, Unilever NV, 'The European Challenge', EDO/CB Conference:'Wrapping it up in the 1990s', London, 18 July.

Munipov, V.M (1992). Chernobyl operators: criminals or victims? Applied Ergonomics 337-342

Pagano, R.R. (2004). Understanding Statistics in the Behavioral Sciences (7th ed.) Thompson/Wadsworth, Belmont, CA, USA

Stellman J. M. (1998) Encyclopaedia of Occupational Health and Safety. Electronic books. International Labo Office, ISBN: 9789221092032

Subramaniam, S. K. Hamidon, A. H. And Singh R. S. S. ( 2009). Optimization of available resources and methods of capitalizing human capital on industrial process lines efficiently. Wseas Transactions $O$ Systems. (6)8:773-782

Willy, M., Robert, R. (2006). Disability and Work.,Encylopaedia of occupational safety and Health. Available from http://www.ilo org/encyclopaedia/. Accessed October 12, 2016.

Wolffang, L. and Joachim, V. (1998). Encyclopaedia of Occupational Health and Safety 4th Edition. Available from http://www.ilocis.org/documents/chp 29e.htm. Accessed May 12, 2016.

Workplace Safety \& Prevention Services (2013) Machine Safety

http://www.wsps.ca/wsps/media/site/resou rces/downloads/wsps machine-

safety 2013 Accessed August 3, 2016 